\title{
ALTERAÇÕES NOS TEORES NUTRICIONAIS FOLIARES DE BANANEIRA 'PRATA-ANÃ' ADUBADA COM COMPOSTO ORGÂNICO EM CINCO CICLOS DE PRODUÇÃO'
}

\author{
ERVAL RAFAEL DAMATTO JUNIOR ${ }^{2}$, ROBERTO LYRA VILLAS BÔAS ${ }^{3}$, EDSON SHIGUEAKI \\ NOMURA $^{2}$, EDUARDO JUN FUZITANI ${ }^{2}$, VALÉRIA AUGUSTA GARCIA ${ }^{2}$
}

RESUMO - O presente trabalho objetivou avaliar o estado nutricional da bananeira-'Prata-anã' durante cinco ciclos de cultivo com adubação orgânica, no município de Botucatu-SP. As plantas foram adubadas com composto orgânico produzido a partir de serragem de madeira e esterco bovino, em que os tratamentos foram constituídos de doses desse composto $\left(0 ; 98,5 ; 197,0 ; 290,5\right.$ e 394,0 g de $\mathrm{K}_{2} \mathrm{O}$ /planta). Empregou-se delineamento experimental em blocos casualizados, com cinco tratamentos e cinco repetições. No florescimento das plantas em cada ciclo, foram retiradas amostras foliares de duas plantas por parcela para serem analisados os teores de nitrogênio, fósforo, potássio, cálcio, magnésio, enxofre, boro, cobre, ferro, manganês e zinco. A maior parte dos macronutrientes presentes nas folhas não foi influenciada pelo incremento de doses de composto orgânico. No decorrer dos ciclos avaliados, os teores foliares de nitrogênio, fósforo, potássio, enxofre, boro, ferro e manganês diminuíram, enquanto o cálcio e o magnésio se acumularam nas plantas. Os teores de potássio estavam abaixo dos padrões para a cultura no Estado de São Paulo, em todos os anos avaliados, mesmo assim as plantas não apresentaram sintomas de deficiência ou queda de produção, inferindo-se que a faixa considerada como adequada para a cultivar pode ser inferior aos padrões atualmente adotados.

Termos para indexação: Musa sp., banana, adubação orgânica, nutrição, potássio.

\section{CHANGES IN NUTRITIONAL LEAVES OF BANANA 'PRATA-ANÃ' FERTILIZED WITH ORGANIC COMPOST FOR FIVE PRODUCTION CYCLES}

\begin{abstract}
This work aimed to assess the nutritional status of banana 'Prata-anã' leaves for five cycles of cultivation with organic fertilization, in Botucatu, SP, Brazil. Plants were fertilized with organic compost produced with wood residue and cattle manure. Treatments consisted of the compost rates $\left(0,98.5,197.0,290.5\right.$ and $394.0 \mathrm{~g}$ of $\mathrm{K}_{2} \mathrm{O}$ per plant). The experiment was arranged in a randomized block design, with 5 treatments and 5 replications. At blooming, leaves of two plants were collected to analyze the levels of nitrogen, phosphorus, potassium, calcium, magnesium, sulfur, boron, copper, iron, manganese and zinc. The content of most nutrients in leaves was not influenced by the increasing rates of organic compost. During the cycles assessed the levels of leaf nitrogen, phosphorus, potassium, sulfur, boron, iron and manganese decreased, whereas there was an increase of the calcium and magnesium contents. The levels of potassium were below the standards for the cultivar in the state of São Paulo, for all the years studied, and yet plants did not show symptoms of weakness or collapse of production. It can be conclude that the range considered appropriate for the culture may be lower than the standards currently adopted.
\end{abstract}

Index terms: Musa sp., banana, organic fertilization, nutrition, potassium.

\footnotetext{
${ }^{1}$ Trabalho Sinfruit 124 - Simpósio Internacional de Fruticultura - Avanços na Fruticultura (17 a 21 Outubro)

${ }^{2}$ Pesquisadores científicos da APTA, Pólo Regional do Vale do Ribeira. - Rod. Régis Bittencourt, km 460, Cx. P:122, Cep: 11900000, Registro-SP. E-mail: erval@apta.sp.gov.br; edsonnomura@apta.sp.gov.br, edufuzitani@apta.sp.gov.br; val.garcia@uol.com.br ${ }^{3}$ Prof. Dr. do Depto. de Recursos Naturais - Solos da Faculdade de Ciências Agronômicas/UNESP, Cep: 18610-307 - Botucatu-SP. E-mail: rlvboas@fca.unesp.br.
} 


\section{INTRODUÇÃO}

A bananicultura tem evoluído consideravelmente nas últimas três décadas, por ser um dos cultivos perenes de mais rápido retorno do capital investido, apresentando um fluxo contínuo de produção a partir do primeiro ano, o que a torna muito atraente para os agricultores. A produção mundial atingiu 97,4 milhões de toneladas em 2009, destacando-se o Brasil como quarto país produtor, com uma produção de 6,8 milhões de toneladas (FAO, 2011), e também como maior consumidor, sendo responsável por aproximadamente $10 \%$ desse total (AGRIANUAL, 2006).

Apesar de ser cultivada em diversos tipos de solos, a bananeira prefere solos ricos em matéria orgânica, bem drenados, argilosos, que possuam boa capacidade de retenção de água e topografia favorável (RANGEL, 1997). Porém, a realidade das regiões produtoras é de solos pobres em nutrientes e também de baixo índice de matéria orgânica.

Campo Dall'Orto et al. (1996) comentam que o principal efeito da adubação orgânica é na melhoria das propriedades físicas e químicas do solo. A matéria orgânica é responsável por algumas reações químicas que ocorrem no solo, como complexação de elementos tóxicos e micronutrientes, influencia na capacidade de troca catiônica e $\mathrm{pH}$, além de fornecer nutrientes às plantas. Assim sendo, estudos relacionados com adubação orgânica e os benefícios que ela pode trazer não só com o aumento de produtividade, bem como com as melhorias nas características físico-químicas destes solos são de fundamental importância para uma boa recomendação de adubação na cultura da bananeira.

A diagnose foliar é atualmente recomendada para aprimorar os ajustes no programa de adubação e principalmente para avaliar a necessidade de aplicação de micronutrientes, e para uma adequada diagnose, diversos fatores que interferem nos teores de nutrientes nas folhas de bananeira devem ser levados em consideração. Martin-Prevél (1977) classifica esses em: fatores internos, como cultivar, estádio fenológico das plantas, posição e porção das folhas e externos, como clima, solo, parasitismo e tratos culturais. Níveis adequados de nutrientes em folhas, das mais diversas cultivares de bananeira, ainda não foram estabelecidos, mas vários autores admitem faixas adequadas para macro e micronutrientes para algumas cultivares em diversas condições (JONES JR. et al., 1991; ROBINSON, 1986; RIBEIRO et al., 1999; PREZOTTI, 1992; RAIJ et al., 1997).

Diante da falta de informações mais precisas sobre teores de nutrientes foliares adequados para as mais diversas cultivares de bananeira, bem como a pouca quantidade de informações sobre adubação orgânica, o presente trabalho objetivou avaliar o estado nutricional de plantas de bananeira-'Prata-anã' durante cinco ciclos de cultivo com adubação orgânica, no município de Botucatu-SP.

\section{MATERIAL E MÉTODOS}

O trabalho foi conduzido no pomar experimental da Faculdade de Ciências Agronômicas (FCA/UNESP), município de Botucatu-SP $\left(22^{\circ} 52^{\prime}\right.$ $\mathrm{S}, 48^{\circ} 26^{\prime} \mathrm{W}$ e altitude $786 \mathrm{~m}$ ), que apresenta clima temperado quente (mesotérmico), com chuvas no verão e seca no inverno (Cwa - Köeppen), e temperatura média mais quente superior a $22^{\circ} \mathrm{C}$ (CUNHA et al., 1999), num solo classificado como Nitossolo Vermelho.

$\mathrm{O}$ experimento foi instalado em novembro de 2002, com mudas convencionais de bananeira cv. Prata-anã (Musa AAB), adotando-se o espaçamento de 2,5 m entre linhas e 2,5 m entre plantas, sendo as plantas adubadas com composto orgânico produzido a partir de serragem de madeira e esterco bovino devidamente compostados. Adotou-se o sistema de irrigação localizada (microaspersão), com vazão de emissores de $40 \mathrm{~L} \mathrm{~h}^{-1}$.

Os tratamentos empregados foram constituídos de diferentes doses de composto orgânico: T1 $=0 \mathrm{~g}$ de $\mathrm{K}_{2} \mathrm{O} /$ planta (Testemunha); $\mathrm{T} 2=98,5 \mathrm{~g}$ de $\mathrm{K}_{2} \mathrm{O} /$ planta; $\mathrm{T} 3=197,0 \mathrm{~g}$ de $\mathrm{K}_{2} \mathrm{O} /$ planta; $\mathrm{T} 4=290,5$ $\mathrm{g}$ de $\mathrm{K}_{2} \mathrm{O} /$ planta; $\mathrm{T} 5=394,0 \mathrm{~g}$ de $\mathrm{K}_{2} \mathrm{O} /$ planta, sendo estas doses de composto calculadas de acordo com o teor de potássio presente no composto.

A adubação anual, utilizando o composto como fonte de nutrientes no primeiro ciclo (2003), foi dividida em cinco parcelas, aplicadas a cada dois meses, nas quantidades determinadas para cada tratamento. Os tratamentos (doses de adubação orgânica) não foram aplicados para a produção das plantas do $2^{\circ}$ e $3^{\circ}$ ciclos (2004 e 2005), objetivando diminuir os teores de potássio no solo e nas plantas da família. Para a produção do $4^{\circ}$ e $5^{\circ}$ ciclos (2006 e 2007), a adubação foi retomada, sendo que o parcelamento da adubação do $4^{\circ}$ ciclo foi feito em três etapas, visando a suprir as exigências das plantas desse ciclo; dessa forma, a primeira parcela foi aplicada em agosto de 2005 , com $30 \%$ do total a ser aplicado neste ciclo, a segunda adubação foi realizada em outubro, aplicando-se $23 \%$ da adubação e, no mês de janeiro de 2006, aplicou-se o restante da adubação (47\%), uma vez que se fosse realizado mais um parcelamento, este adubo estaria sendo aplicado, em parte, para as plantas do ciclo seguinte. Para o $5^{\circ}$ ciclo, a adubação foi 
parcelada em quatro vezes, tendo sido aplicados $30 \%$ no mês de junho, $25 \%$ em agosto, $25 \%$ em outubro e $20 \%$ em novembro de 2006 . Tal modificação no parcelamento do composto ocorreu com o objetivo de melhor distribuir a adubação durante o ciclo.

Empregou-se delineamento experimental em blocos casualizados, com cinco tratamentos, cinco repetições e duas plantas úteis por parcela. Os dados foram submetidos à análise de variância, e para os parâmetros considerados significativos pelo teste $\mathrm{F}$, foi realizada análise de regressão.

No florescimento das plantas em cada ciclo (2003, 2004, 2005, 2006 e 2007), retiraram-se amostras foliares de duas plantas úteis por parcela, coletadas da $3^{\mathrm{a}}$ folha a partir do ápice. Foram utilizados $10 \mathrm{~cm}$ da parte interna mediana do limbo foliar, eliminando-se a nervura central, conforme recomendações da norma internacional (MARTIN-PRÉVEL, 1984). As folhas foram lavadas e secas em estufa a $65^{\circ} \mathrm{C}$ e encaminhadas ao Laboratório de Nutrição Mineral de Plantas do Departamento de Recursos Naturais - Solo, onde se realizou a análise química, segundo metodologia descrita por Malavolta et al. (1997). Foram analisados os teores de nitrogênio, fósforo, potássio, cálcio, magnésio, enxofre, boro, cobre, ferro, manganês e zinco.

\section{RESULTADOS E DISCUSSÃO}

Os teores de nutrientes na massa seca foliar da bananeira-'Prata-anã' mostraram a seguinte ordem de concentração no florescimento do $1^{\circ}$ ciclo de produção: $\mathrm{K}>\mathrm{N}>\mathrm{Ca}>\mathrm{Mg}>\mathrm{S}>\mathrm{P}$. A partir do $2^{\circ}$ ciclo, os teores de fósforo foram maiores que os de enxofre, mostrando as seguinte ordem de concentração: $\mathrm{K}>\mathrm{N}>\mathrm{Ca}>\mathrm{Mg}>\mathrm{P}>\mathrm{S}$, com médias de 34; 27; 8; 3,7; 2,2 e $1,8 \mathrm{~g} \mathrm{~kg}^{-1}$ no $2^{\circ}$ ciclo; $29 ; 24 ; 9 ; 4,6 ; 1,9$ e $1,6 \mathrm{~g}$ $\mathrm{kg}^{-1}$ no $3^{\circ}$ ciclo, e $28 ; 22 ; 9 ; 4,4 ; 1,9$ e $1,5 \mathrm{~g} \mathrm{~kg}^{-1}$ no $4^{\circ}$ ciclo. No $5^{\circ}$ ciclo, a mesma ordem de concentração de nutrientes do primeiro ciclo se repetiu, apresentando teores médios de 23; 22; 11; 4,6; 1,6 e 1,5 g $\mathrm{kg}^{-1}$ para $\mathrm{K}, \mathrm{N}, \mathrm{Ca}, \mathrm{Mg}, \mathrm{S}$ e $\mathrm{P}$, respectivamente.

No decorrer dos ciclos avaliados, os teores foliares de nitrogênio, fósforo, potássio e enxofre diminuíram, passando em média de $30 ; 2,0 ; 31 ; 2,5 \mathrm{~g}$ $\mathrm{kg}^{-1}$ no $1^{\circ}$ ciclo para $22 ; 1,5 ; 23 ; 1,6 \mathrm{~g} \mathrm{~kg}^{-1}$ no $5^{\circ}$ ciclo, respectivamente, como pode ser observado na Tabela 2 , enquanto o cálcio e o magnésio foram acumulados nas plantas no decorrer dos ciclos, passando de $9 \mathrm{e}$ $3,2 \mathrm{~g} \mathrm{~kg}^{-1}$ para 11 e 4,6 $\mathrm{g} \mathrm{kg}^{-1}$, respectivamente.

No período de cinco ciclos de avaliação, os teores foliares médios de nitrogênio apresentaram resposta aos tratamentos de adubação orgânica aplicada, contudo seus valores, em todos os tratamentos, estavam abaixo dos teores tidos como adequados para a cultura, que varia de 27 a $36 \mathrm{~g} \mathrm{~kg}^{-1}$ (RAIJ et al., 1997), como pode ser observado na Tabela 1 , onde se verifica que os teores foliares deste nutriente foi de $25 \mathrm{~g} \mathrm{~kg}^{-1}$, valor muito próximo do mínimo da faixa considerada adequada para a cultura, sendo possivelmente por esse motivo que não foram observados sintomas de deficiência de nitrogênio nas plantas.

Avaliando-se apenas o $1^{\circ}$ e $2^{\circ}$ ciclos, os teores de nitrogênio determinados nas folhas da bananeira-'Prata-anã' encontravam-se, segundo os padrões nutricionais conhecidos (RAIJ et al., 1997), adequados no momento do florescimento, não havendo diferenças entre tratamentos e apresentando valores médios de 30 e $27 \mathrm{~g} \mathrm{~kg}^{-1}$, respectivamente. Mas, a partir do $3^{\circ}$ ciclo, seus teores foliares estavam abaixo do padrão da cultura, apresentando teores médios de 24; 22 e $22 \mathrm{~g} \mathrm{~kg}^{-1}$, no $3^{\circ}, 4^{\circ}$ e $5^{\circ}$ ciclos, respectivamente (Tabela 2).

Apenas no $4^{\circ}$ ciclo foi observada influência da adubação com composto orgânico nos teores foliares de nitrogênio, em que a sua maior concentração $\left(23 \mathrm{~g} \mathrm{~kg}^{-1}\right)$ se deu nas plantas adubadas com $197 \mathrm{~g}$ de potássio por planta, indicando que, nesta fase, o composto orgânico aplicado ao solo foi um bom fornecedor deste nutriente às plantas.

Os teores foliares de fósforo não foram influenciados pelos tratamentos, contudo seus teores foliares encontravam-se dentro de uma faixa considerada adequada para o bom desenvolvimento da cultura, como pode ser observado na Tabela 1. Apenas no $5^{\circ}$ ciclo, as folhas mostraram-se com teores de fósforo abaixo do padrão, que varia de 1,8 a 2,7 $\mathrm{g} \mathrm{kg}^{-1}$, e os teores apresentados nas folhas foram de $1,5 \mathrm{~g} \mathrm{~kg}^{-1}$, sem que as plantas apresentassem sintomas visuais de sua carência.

O potássio, que é o elemento requerido em maiores quantidades pelas bananeiras, não apresentou resposta aos tratamentos de adubação orgânica aplicada, sendo que os seus teores médios nas folhas foram de $29 \mathrm{~g} \mathrm{~kg}^{-1}$, teor bastante abaixo da faixa considerada adequada para a cultura (35 a $54 \mathrm{~g} \mathrm{~kg}^{-1}$ ). Mesmo seus teores foliares não estando próximos a esta faixa, as plantas não apresentaram sintomas de sua deficiência, e a produtividade obtida também foi adequada $\left(26,4 \mathrm{t} \mathrm{ha}^{-1}\right.$ no $1^{\mathrm{o}}$ ciclo; $27,3 \mathrm{t} \mathrm{ha} \mathrm{a}^{-1}$ no $2^{\circ}$ ciclo; 22,5 t ha $^{-1}$ no $3^{\circ}$ ciclo, e 20,9 t ha ${ }^{-1}$ no $4^{\circ}$ ciclo), quando se compara com a média nacional, que em 2009 foi de 19,8 tha $^{-1}$, segundo dados da FAO (2011).

É interessante observar que os teores de potássio não se alteraram entre a testemunha e a dose mais elevada de composto, indicando que, se ocorreu a chamada "absorção de luxo", o potássio não permaneceu na folha, sendo translocado para outros órgãos 
ou até mesmo para as outras plantas da família, que possivelmente acabou sendo redistribuído para as outras plantas nos ciclos seguinte.

Os teores foliares de potássio no florescimento do $1^{\circ}$ ciclo foram de $31 \mathrm{~g} \mathrm{~kg}^{-1}$, abaixo do qual é sugerido por Raij et al. (1997), que varia de 35 a $54 \mathrm{~g}$ $\mathrm{kg}^{-1}$, porém em nenhum momento foram observados sintomas de deficiência desse nutriente nas plantas. Semelhantemente ao $1^{\circ}$ ciclo, seus teores foliares mantiveram-se abaixo do padrão em todos os ciclos, com teores foliares médios de 34; 29; 28 e $23 \mathrm{~g} \mathrm{~kg}^{-1}$, no $2^{\circ}, 3^{\circ}, 4^{\circ}$ e $5^{\circ}$ ciclos, respectivamente, como pode ser observado na Tabela 2.

Segundo Lahav e Turner (1983), o potássio é o nutriente mais encontrado nos frutos de bananeira, com isso sua exigência torna-se maior na época de formação do cacho. Gomes (2004), aplicando doses de potássio via fertirrigação, não observou diferença nos teores foliares de potássio. A exemplo deste trabalho, o autor encontrou teores médios de $27 \mathrm{~g}$ $\mathrm{kg}^{-1}$ de potássio nas folhas, abaixo dos citados por Raij et al. (1997), com produção de $17 \mathrm{t} \mathrm{ha}^{-1}$ para a bananeira-'Prata-anã'. Guerra (2001), trabalhando com fertirrigação em bananeira-'Prata-anã', notou que os teores foliares de potássio estavam abaixo dos níveis adequados para a bananeira. Resultados semelhantes foram encontrados por Teixeira (2000) em um mesmo tipo de solo e sob irrigação.

Diante dos resultados obtidos neste trabalho e nos de outros autores, como Gomes (2004), Guerra (2001) e Teixeira (2000), é possível sugerir que, para a bananeira-'Prata-anã', a faixa adequada de potássio está entre 25 e $30 \mathrm{~g} \mathrm{~kg}^{-1}$. Malavolta (1979) sugere que o teor foliar adequado para bananeira seria de

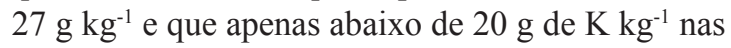
folhas, as plantas seriam consideradas deficientes para este nutriente. Para Prezotti (1992) e Raij et al. (1997), a faixa de concentração de potássio em folhas de bananeira deve estar entre 32 e $54 \mathrm{~g} \mathrm{~kg}^{-1}$, enquanto Robinson (1986) cita ser esta faixa mais estreita (31 a $40 \mathrm{~g} \mathrm{~kg}^{-1}$ ). Ribeiro et al. (1999) cita como teor adequado $28 \mathrm{~g} \mathrm{~kg}^{-1}$ e Jones Jr. et al. (1991) 38 a 50 $\mathrm{g} \mathrm{kg}^{-1}$. Portanto, a indicação de teores adequados de potássio em folhas de bananeiras é bastante variável, sugerindo estudos de teores adequados de nutrientes nas folhas de bananeira específicos para as cultivares.

Os teores de cálcio nas folhas, no florescimento do $1^{\circ}$ e $4^{\circ}$ ciclos, não mostraram diferença entre os tratamentos (doses de composto), enquanto os maiores teores foliares de magnésio no florescimento do $1^{\circ}$ ciclo $\left(3,4 \mathrm{~g} \mathrm{~kg}^{-1}\right)$ foram encontrados no tratamento que recebeu a maior dose de composto (394 g / planta), mostrando que este composto, utilizado como fonte de adubo, é um bom fornecedor de magnésio. No $2^{\circ}$ ciclo, os teores de cálcio e magnésio mostraram diferenças significativas, em que os maiores teores foliares de cálcio foram encontrados nas plantas adubadas com a maior dose de composto, e os de magnésio, com a aplicação das duas maiores doses de composto.

Semelhantemente ao observado para os teores foliares de nitrogênio e potássio, os teores foliares médios de enxofre não mostraram resposta à adubação orgânica aplicada, e seus teores médios encontravam-se abaixo da faixa adequada para a cultura, porém sintomas de sua deficiência não foram observados.

No $1^{\circ}$ ciclo, os níveis de enxofre apresentavam-se próximos do limite inferior da faixa compreendida como adequada, que varia de 2,5 a $8,0 \mathrm{~g} \mathrm{~kg}^{-1}$ (RAIJ et al., 1997), uma vez que não foi adicionada outra fonte de nutriente que o contivesse, apresentando em média 2,5 $\mathrm{g} \mathrm{kg}^{-1}$. A partir do $2^{\circ}$ ciclo, foi observado que os teores foliares de enxofre se encontravam abaixo do padrão adequado à cultura. Seus teores médios foram de 1,8; 1,6; 1,5 e 1,6 $\mathrm{g} \mathrm{kg}^{-1}$ no $2^{\circ}, 3^{\circ}, 4^{\circ}$ e $5^{\circ}$ ciclos, respectivamente (Tabela 2 ).

De maneira geral, os tratamentos não influenciaram significativamente sobre os teores foliares de micronutrientes, como pode ser observado na Tabela 3. Isso mostra que a concentração de micronutrientes em compostos orgânicos, em especial ao utilizado neste trabalho, é relativamente baixa, sendo que, em algumas situações, é necessária a aplicação adicional de outros micronutrientes, como ocorreu com o boro, que foi complementado no $1^{\circ}$ ciclo com aplicação de $10 \mathrm{~g}$ de ácido bórico por planta.

A ordem de concentração foliar dos micronutrientes manteve-se a mesma para todos os ciclos $(\mathrm{Mn}>\mathrm{Fe}>\mathrm{B}>\mathrm{Zn}>\mathrm{Cu})$, com pequenas variações em seus teores médios.

O teor foliar de boro foi o único que se encontrava acima da faixa considerada adequada para a cultura, que varia de 10 a $25 \mathrm{mg} \mathrm{kg}^{-1}$, sendo que seus teores foliares médios foram $45 \mathrm{mg} \mathrm{kg}^{-1}$, mas, visualmente, algumas plantas apresentaram folhas com sintomas característicos de sua deficiência. Dessa forma, para suprir as necessidades da planta com boro, realizou-se a aplicação de ácido bórico, na dose de $10 \mathrm{~g}$ por planta, como é recomendado por Raij et al. (1997), em duas parcelas no $1^{\circ}$ ciclo da cultura, sendo que esse boro aplicado pode ter sido acumulado nas plantas da família que o redistribuíram para as plantas dos ciclos seguintes, mantendo dessa forma seus teores foliares elevados. Pela Tabela 4, é possível verificar-se que seus teores foliares tiveram redução do primeiro para os demais ciclos, partindo de um teor médio de $54 \mathrm{mg} \mathrm{kg}^{-1}$ e chegando 
a um valor mínimo de $40 \mathrm{mg} \mathrm{kg}^{-1}$ no $4^{\circ}$ ciclo (2006).

Devido a essa suplementação de boro ao solo, nos ciclos subsequentes, seus teores foliares estavam acima do padrão adequado para a cultura, que varia de 10 a $25 \mathrm{mg} \mathrm{kg}^{-1}$, sendo que as plantas apresentavam os seguintes teores foliares no $2^{\circ}, 3^{\circ}$, $4^{\circ}$ e $5^{\circ}$ ciclos: $45 ; 41 ; 40$ e $43 \mathrm{mg} \mathrm{kg}^{-1}$. No $5^{\circ}$ ciclo, o boro foi o único micronutriente que mostrou resposta aos tratamentos aplicados em campo, mostrando queda linear com o aumento das doses de composto orgânico aplicado ( $\left.\hat{y}=-3,6 x+53,8 ; R^{2}=0,6480\right)$.

Os teores foliares de cobre, ferro e manganês apresentaram-se adequados para a cultura, como pode ser observado na Tabela 3 , enquanto os teores de zinco estavam abaixo da faixa considerada adequada para a cultura.

Pela Tabela 4, é possível observar-se que a mesma tendência de redução ocorrida nos teores foliares de boro repetiu-se para os teores foliares de ferro e manganês, que tiveram seus maiores valores encontrados nas folhas do $1^{\circ}$ ciclo (2003), seguido de queda significativa no $2^{\circ}$ ciclo (2004), e, a partir deste ano, manteve-se estável até o $5^{\circ}$ ciclo (2007).

Os teores foliares de cobre e zinco oscilaram durante os ciclos avaliados, sendo que seus maiores valores foram observados no $4^{\circ}$ ciclo (2006), e os menores, no $2^{\circ}$ ciclo (2004) para o cobre e no $1^{\circ}$ para o zinco, como pode ser observado na Tabela 4.

No $2^{\circ}$ e $3^{\circ}$ ciclos, foi possível verificar que os teores de zinco estavam abaixo da faixa considerada ideal para a cultura, porém sintomas de deficiência de zinco não foram observados nas plantas. No $4^{\circ}$ ciclo, a adubação foi retomada e não mais foi observada a deficiência de zinco, indicando que o composto apresentava quantidade suficiente de zinco para suprir as necessidades da planta; contudo, no $5^{\circ}$ ciclo, seus teores foliares voltaram a ficar abaixo da faixa considerada adequada, apresentando teores médios de $15 ; 13$ e $15 \mathrm{mg} \mathrm{kg}^{-1}$ no $2^{\circ}, 3^{\circ}$ e $5^{\circ}$ ciclos, respectivamente.

TABELA 1 - Teores médios de macronutrientes $\left(\mathrm{g} \mathrm{kg}^{-1}\right)$ encontrados em folhas de bananeira adubadas com doses de composto orgânico. Botucatu-SP (2002 a 2007).

\begin{tabular}{lcccccc}
\hline Tratamentos & Nitrogênio & Fósforo & Potássio & Cálcio & Magnésio & Enxofre \\
\hline T1: 0 g de potássio / planta & $26 \mathrm{a}$ & 1,9 & 29 & 9 & 4,1 & 1,8 \\
T2: 98,5 g de potássio / planta & $24 \mathrm{~b}$ & 1,9 & 29 & 9 & 3,9 & 1,8 \\
T3: 197,0 g de potássio / planta & $25 \mathrm{ab}$ & 1,9 & 29 & 9 & 4,0 & 1,8 \\
T4: 290,5 g de potássio / planta & $25 \mathrm{ab}$ & 1,9 & 27 & 10 & 4,3 & 1,8 \\
T5: 394,0 g de potássio / planta & $25 \mathrm{ab}$ & 1,9 & 29 & 10 & 4,2 & 1,8 \\
\hline \multicolumn{1}{c}{ Médias } & 25 & 1,9 & 29 & 9 & 4,1 & 1,8 \\
\hline \multicolumn{1}{c}{ Padrão* } & $27-36$ & $1,8-2,7$ & $35-54$ & $3-12$ & $3-6$ & $2,5-8,0$ \\
\hline CV (\%) & 5,71 & 11,92 & 14,94 & 22,87 & 14,61 & 14,65 \\
\hline
\end{tabular}

Médias seguidas por letras distintas na coluna diferem pelo teste de Tukey, a 5\% de probabilidade.

* Fonte: Boletim Técnico 100, IAC, 1997.

TABELA 2 - Teores médios de macronutrientes $\left(\mathrm{g} \mathrm{kg}^{-1}\right)$ encontrados em folhas de bananeira adubadas com doses de composto orgânico, durante cinco anos de avaliação. Botucatu-SP (2002 a 2007).

\begin{tabular}{ccccccc}
\hline Ciclos (Anos) & Nitrogênio & Fósforo & Potássio & Cálcio & Magnésio & Enxofre \\
\hline $1^{\circ}$ ciclo (2003) & $30 \mathrm{a}$ & $2,0 \mathrm{ab}$ & $31 \mathrm{ab}$ & $9 \mathrm{~b}$ & $3,2 \mathrm{~b}$ & $2,5 \mathrm{a}$ \\
$2^{\circ}$ ciclo (2004) & $27 \mathrm{~b}$ & $2,2 \mathrm{a}$ & $34 \mathrm{a}$ & $8 \mathrm{~b}$ & $3,7 \mathrm{~b}$ & $1,8 \mathrm{~b}$ \\
$3^{\circ}$ ciclo (2005) & $24 \mathrm{c}$ & $1,9 \mathrm{~b}$ & $29 \mathrm{bc}$ & $9 \mathrm{~b}$ & $4,6 \mathrm{a}$ & $1,6 \mathrm{bc}$ \\
$4^{\circ}$ ciclo (2006) & $22 \mathrm{~d}$ & $1,9 \mathrm{~b}$ & $28 \mathrm{c}$ & $9 \mathrm{~b}$ & $4,4 \mathrm{a}$ & $1,5 \mathrm{c}$ \\
$5^{\circ}$ ciclo (2007) & $22 \mathrm{~d}$ & $1,5 \mathrm{c}$ & $23 \mathrm{~d}$ & $11 \mathrm{a}$ & $4,6 \mathrm{a}$ & $1,6 \mathrm{bc}$ \\
\hline Médias & 25 & 1,9 & 29 & 9 & 4,1 & 1,8 \\
\hline Padrão* & $27-36$ & $1,8-2,7$ & $35-54$ & $3-12$ & $3-6$ & $2,5-8,0$ \\
\hline CV $(\%)$ & 5,71 & 11,92 & 14,94 & 22,87 & 14,61 & 14,65 \\
\hline
\end{tabular}

Médias seguidas por letras distintas na coluna diferem pelo teste de Tukey, a $5 \%$ de probabilidade.

* Fonte: Boletim Técnico 100, IAC, 1997. 
TABELA 3 - Teores médios de micronutrientes $\left(\mathrm{mg} \mathrm{kg}^{-1}\right)$ encontrados em folhas de bananeira adubadas com doses de composto orgânico. Botucatu-SP (2002 a 2007).

\begin{tabular}{lccccc}
\hline Tratamentos & Boro & Cobre & Ferro & Manganês & Zinco \\
\hline T1: 0 g de potássio / planta & 43 & 8 & 121 & 637 & 15 \\
T2: 98,5 g de potássio / planta & 44 & 7 & 120 & 664 & 14 \\
T3: 197,0 g de potássio / planta & 46 & 7 & 127 & 639 & 15 \\
T4: 290,5 g de potássio / planta & 47 & 7 & 126 & 631 & 14 \\
T5: 394,0 g de potássio / planta & 43 & 7 & 143 & 608 & 15 \\
\hline \multicolumn{1}{c}{ Médias } & 45 & 7 & 128 & 636 & 15 \\
\hline Padrão* & $10-25$ & $6-30$ & $80-360$ & $200-2000$ & $20-50$ \\
\hline CV $(\%)$ & 22,10 & 17,46 & 39,00 & 34,94 & 9,34 \\
\hline
\end{tabular}

Médias seguidas pelas mesmas letras na coluna não diferem pelo teste de Tukey, a 5\% de probabilidade.

* Fonte: Boletim Técnico 100, IAC, 1997.

TABELA 4 - Teores médios de micronutrientes $\left(\mathrm{mg} \mathrm{kg}^{-1}\right)$ encontrados em folhas de bananeira adubadas com doses de composto orgânico, durante cinco anos de avaliação. Botucatu-SP (2002 a 2007).

\begin{tabular}{cccccc}
\hline Anos & Boro & Cobre & Ferro & Manganês & Zinco \\
\hline 2003 & $54 \mathrm{a}$ & $7 \mathrm{~b}$ & $182 \mathrm{a}$ & $1064 \mathrm{a}$ & $11 \mathrm{~d}$ \\
2004 & $45 \mathrm{~b}$ & $6 \mathrm{c}$ & $112 \mathrm{~b}$ & $487 \mathrm{~b}$ & $15 \mathrm{~b}$ \\
2005 & $41 \mathrm{~b}$ & $8 \mathrm{~b}$ & $123 \mathrm{~b}$ & $494 \mathrm{~b}$ & $13 \mathrm{c}$ \\
2006 & $40 \mathrm{~b}$ & $10 \mathrm{a}$ & $123 \mathrm{~b}$ & $631 \mathrm{~b}$ & $20 \mathrm{a}$ \\
2007 & $43 \mathrm{~b}$ & $5 \mathrm{~d}$ & $97 \mathrm{~b}$ & $504 \mathrm{~b}$ & $15 \mathrm{~b}$ \\
\hline Médias & 45 & 7 & 128 & 636 & 15 \\
\hline Padrão* & $10-25$ & $6-30$ & $80-360$ & $200-2000$ & $20-50$ \\
\hline CV (\%) & 22,10 & 17,46 & 39,00 & 34,94 & 9,34 \\
\hline
\end{tabular}

Médias seguidas por letras distintas na coluna diferem pelo teste de Tukey, a $5 \%$ de probabilidade.

* Fonte: Boletim Técnico 100, IAC, 1997.

\section{CONCLUSÕES}

1. A maior parte dos macronutrientes presentes nas folhas da bananeira-'Prata-anã' não foi influenciada pelo incremento de doses de composto orgânico.

2. No decorrer dos ciclos avaliados, os teores foliares de nitrogênio, fósforo, potássio, enxofre, boro, ferro e manganês diminuíram, enquanto o cálcio e o magnésio se acumularam nas plantas.

3. Devido aos teores estarem abaixo dos padrões para a cultura no Estado de São Paulo e as plantas não apresentarem sintomas de deficiência ou queda significativa de produção, infere-se que a faixa considerada como adequada para a cultura e para esta cultivar deve ser inferior aos padrões atualmente adotados para a cultura.

4. Os teores foliares de micronutrientes, excetuando-se o zinco, estavam adequados para a cultura em todos os ciclos, indicando que o composto aplicado foi eficaz para suprir as necessidades das bananeiras com os principais micronutrientes.

\section{REFERÊNCIAS}

AGRIANUAL 2006: anuário estatístico da agricultura brasileira. São Paulo: FNP Consultoria \& Comércio, 2005. 504 p.

CAMPO DALL'ORTO, F.A. et al. Frutas de clima temperado II: Figo, maçã, marmelo, pera e pêssego em pomar compacto. In: RAIJ, B. van. et al. (Ed.). Recomendações de adubação e calagem para o Estado de São Paulo. 2.ed. Campinas: Fundação Instituto Agronômico, 1996. p.139-140.

CUNHA, A.R.; KLOSOWSKI, E.S.; GALVANI, E.; SCOBEDO, J.F.; MARTINS, D. Classificação climática para o município de Botucatu-SP, segundo Köeppen. In: SIMPÓSIO EM ENERGIA NAAGRICULTURA, 1., 1999, Botucatu. Anais... Botucatu: Faculdade de Ciências Agronômicas, Universidade Estadual Paulista, 1999. p.487-491. 
FAO - Food and Agriculture Organization, 2011. Disponível em: $<$ http://faostat.fao.org/faostat $>$. Acesso em: 30 jun. 2011.

GOMES, E.M. Crescimento e produção de bananeiras-'Prata-anã' e 'Maçã' fertirrigadas com potássio. 2004. 76f. Tese (Doutorado em Agronomia) - Faculdade de Ciências Agronômicas, Universidade Estadual Paulista, Botucatu, 2004.

GUERRA, A.G. Fertirrigação com nitrogênio e potássio utilizando sistema de irrigação por microaspersão na cultura da bananeira 'Prata-anã'. 2001. 69f. Tese (Doutorado em Agronomia) - Faculdade de Ciências Agrária e Veterinárias, Universidade Estadual Paulista, Jaboticabal, 2001.

JONES JR., J.B.; WOLF, B.; MILLS, H.A. Plant analyses handbook: a practical sampling, preparation, analyses and interpretation guide. Athens: Micro-Macro Publishing, 1991. 213p.

LAHAV, E.; TURNER, D.W. Banana nutrition. Bern: International Potash Institute, 1983. 62p. (Bulletin, 7).

MALAVOLTA, E. Potássio, magnésio e enxofre nos solos e culturas brasileiras. Piracicaba: Franciscana, 1979. 92p. (Boletim Técnico, 4).

MALAVOLTA, E.; VITTI, G.C.; OLIVEIRA, S.A. de. Avaliação do estado nutricional das plantas: princípios e aplicações. 2.ed. Piracicaba: POTAFÓS, 1997. 319p.

MARTIN-PRÉVEL, P. Bananier. In : MARTINPRÉVEL, P. ; GAGNARD, J. ; GAUTIER, P. (Eds.) L'analyse végétale dans le contrôle de l'atation des plantes tempérées et tropicales. Paris: Tec \& Doc, 1984. p. 715-751.
MARTIN-PREVÉL, P. Echantillonnange du bananier por l'analyse foliare; cons'equences des differences de techiniques. Fruits, Paris, v.32, n.3, p.151-166, 1977.

PREZOTTI, L.C. Recomendação de calagem e adubação para o Estado do Espírito Santo: $3^{\mathrm{a}}$ aproximação. Vitória: EMCAPA, 1992. 73p. (Circular Técnica, 12).

RAIJ, B. van; CANTARELLA, H.; QUAGGIO, J.A.; FURLANI, A.M.C. (Ed.). Recomendações de adubação e calagem para o Estado de São Paulo. 2.ed. rev. e atual. Campinas: IAC, 1997. 285p. (Boletim Técnico, 100).

RANGEL, A. Banana. In: SÃO PAULO. Secretaria de Agricultura e de Abastecimento. Coordenadoria de Assistência Técnica Integral. Manual técnico das culturas. 2.ed. Campinas, 1997. p.100-110.

RIBEIRO, A.C.; GUIMARÃES, P.T.G.; ALVAREZ, V.H. Recomendações para o uso de corretivos e fertilizante em Minas Gerais: $5^{\text {a }}$ aproximação. Viçosa: CFSEMG, 1999. 359p.

ROBINSON, J.B. Fruits, Vines e Nuts. In: REUTER, D.J.; ROBINSON, J.B. (Ed.). Plant analyses: an interpretation manual. Melbourne: Inkata Press, 1986. p.120-147.

TEIXEIRA, L.A.J. Adubação nitrogenada e potássica em bananeira 'Nanicão' (Musa AAA subgrupo Cavendish) sob duas condições de irrigação. 2000. 130f. Tese (Doutorado em Agronomia) - Faculdade Ciências Agrária e Veterinárias, Universidade Estadual Paulista, Jaboticabal, 2000. 